\title{
Response to Letter to the Editor. Re: Association between kissing and retropositioned ovaries and severity of endometriosis: MR imaging evaluation
}

\author{
Wendaline M. VanBuren ${ }^{1}$
}

Published online: 30 April 2020

(c) Springer Science+Business Media, LLC, part of Springer Nature 2020

This letter is in response to the letter by M. Leonardi and G. Condous who in response to our article [1], highlighted the vital role of ultrasound in the assessment of endometriosis and "kissing ovaries". The points addressed by the authors are valid and noteworthy, however, several portions of the discussion require further clarification. In particular, ultrasound when performed with a dedicated protocol such as those suggested in this edition [2,3] and a skilled operator may achieve excellent results. Routine pelvic ultrasound which is not targeted for endometriosis may underperform when compared to MRI for disease detection [4] for a variety of reasons, but certainly non-dedicated protocols, operator/interpreter inexperience and limited field of view may contribute.

While "kissing ovaries" themselves are a surgical descriptor of characteristic morphologic changes related to endometriosis, until this configuration is identifiable via other modalities it remains a presumption. Both our paper and your letter reference the study which validates this configuration on ultrasound [5]. While not surprising, our study goes on to validate this characteristic positioning at MRI, however, also shows that ovarian positioning has increased disease severity independent of the presence or absence of an endometrioma and shows an increased risk of deep infiltrative endometriosis.

This reply refers to the comment available online at https://doi. org/10.1007/s00261-019-02224-8.

This comment refers to the article available online at https://doi. org/10.1007/s00261-019-02153-6.

Wendaline M. VanBuren

VanBuren.Wendaline@mayo.edu

1 Department of Radiology, Mayo Clinic, Rochester, MN, USA
Our paper highlights the increased disease severity of endometriosis seen in association with "kissing ovaries" and should prompt a thorough search pattern to optimize future possible operative management.

\section{References}

1. Williams JC, Burnett TL, Jones T, Venkatesh SK, Van Buren WM (2019) Association between kissing and retropositioned ovaries and severity of endometriosis: MR imaging evaluation. Abdom Radiol https://doi.org/10.1007/s00261-019-02153-6

2. Chamié, L.P. Ultrasound evaluation of deeply infiltrative endometriosis: technique and interpretation. Abdom Radiol (2019). https ://doi.org/10.1007/s00261-019-02322-7

3. Young, S.W., Groszmann, Y., Dahiya, N. et al. Sonographeracquired ultrasound protocol for deep endometriosis. Abdom Radiol (2019). https://doi.org/10.1007/s00261-019-02341-4

4. Bartlett, D.J., Burkett, B.J., Burnett, T.L. et al. Comparison of routine pelvic US and MR imaging in patients with pathologically confirmed endometriosis. Abdom Radiol (2019). https://doi. org/10.1007/s00261-019-02124-x

5. Ghezzi F, Raio L, Cromi A, et al (2005) "Kissing ovaries": A sonographic sign of moderate to severe endometriosis. Fertil Steril 83:143-7. https://doi.org/10.1016/j.fertnstert.2004.05.094

Publisher's Note Springer Nature remains neutral with regard to jurisdictional claims in published maps and institutional affiliations. 